\title{
ORIGEN Y CONFIGURACIÓN DE UNA MAGISTRATURA DEL SEÑORÍO DEL ARZOBISPO COMPOSTELANO: EL JUEZ SEGLAR DE LA QUINTANA (1545-1599)
}

\author{
por \\ MARÍA LÓPEZ DÍAZ
}

Por extensión de su dominio y número de vasallos, el Arzobispo de Santiago fue durante el Antiguo Régimen uno de los señores más importantes del Reino de Galicia, por delante incluso del Rey (realengo)'. Para gobernar y administrar justicia en tan amplio señorío, que básicamente se localizaba en la provincia de Santiago ${ }^{2}$, contaba con una organización judicial bastante compleja y en ciertos aspectos confusa, pues no procedía de un plan racional de distribución estructural de competencias, sino de

\footnotetext{
' Según ambas magnitudes ocupaba el primer puesto en el ranking de los señores jurisdiccionales gallegos. En 1760, concretamente, era señor de más de 71.400 vasallos (esto es, en torno al $21 \%$ y $13 \%$ de la población y territorio gallego, respectivamente). Por detrás se situaban el conde de Lemos ( $8^{\prime} 45 \%$ y $12^{\prime} 17 \%$, respectivamente) y "Su Magestad" (realengo) ( $8^{\prime} 32 \%$ y $8{ }^{\prime} 84 \%$, respectivamente), seguidos a distancia por los condes de Altamira, Ribadavia y Salvatierra, entre otros (A. EIRAS ROEL, "El señorío gallego en cifras. Nómina y ranking de los señores jurisdiccionales", en Cuadernos de Estudios Gallegos, 103 (1989), pp. 113-136, esp. tabla 2).

${ }^{2}$ Ejercía jurisdicción sobre aproximadamente el $60 \%$ de la población y la mitad de la superficie provincial. Para más información sobre los límites físicos y cartografía de su dominio, remitimos a los trabajos de F.X. RÍO BARJA, Cartografia xurisdiccional de Galicia no século XVIII, Santiago, 1990 y M. LÓPEZ DÍAZ, "Alteraciones en el mapa jurisdiccional gallego durante la Edad Moderna: las desmembraciones eclesiásticas del siglo XVI", en Estudios Mindonienses, 7 (1991), pp. 559-588.
}

"CUADERNOS DE ESTUdIOS GALLEGOS", Tomo XLI, Fascículo 106, Santiago 1993-94. 
una acumulación de instituciones surgidas y desarrolladas en diversas etapas evolutivas; a veces, incluso, con atribuciones similares. Ahora bien, si esto es cierto no lo es menos que a lo largo de las centurias de la modernidad, particularmente durante los siglos XVI y XVII, también hubo en este nivel intermedio (o señorial) - y acéptese, por ahora, la identificación sin mayores cautelas - una progresiva, aunque lenta, especialización y autonomía de las magistraturas. La reestructuración del organigrama judicial con la separación e independencia de los tribunales eclesiásticos y laicos, por un lado, y dentro de los segundos (que interesan a la jurisdicción temporal del Prelado) la institucionalización del llamado juez seglar de la quintana y subsiguiente jerarquización de las audiencias, por otro, son signos inequívocos en este sentido. Analizar cómo, cuándo y por qué se llevó a cabo esta reforma orgánica, en particular las características, funcionamiento y significación de esa nueva magistratura, y no sólo desde el punto de vista jurídico sino también político, será el objeto del presente artículo.

Para centrar el tema comenzaremos por hacer un breve bosquejo del esquema judicial precedente que regía en el dominio del Arzobispo.

Siguiendo el orden esencialmente jerarquizado y piramidal que encuadra al sistema procesal, en la base del mismo se sitúan los tribunales y justicias locales (en la ciudad de Santiago y mayoría de las villas del señorío, alcaldes ordinarios) que en sentido estricto no eran magistraturas señoriales sino municipales, aun cuando fueran nombrados por el señor a propuesta del concejo (sistema de $\operatorname{cobrados}^{3}$ ). En tanto que jueces ordinarios a ellos correspondía conocer en $1^{\mathrm{a}}$ instancia de todas las causas, así civiles como criminales, dentro del ámbito de su jurisdicción.

En el nivel inmediato aparece ya el cuadro de justicias y audiencias señoriales, entre las que no siempre hay una precisa diferenciación funcional. Como pieza clave destaca el alcalde mayor o asistente, heredero directo del "juez de apelaciones" que con el nombre de "corregidor mayor" instituyó el Arzobispo Don Lope de Mendoza (1399-1445), cercenando las atribuciones del pertiguero mayor, hasta entonces poderoso baluarte de la administración señorial ${ }^{4}$. Desconocemos en que momento alcan-

\footnotetext{
${ }^{3}$ Véase, al efecto, S. PORTELA PAZOS, "Diversidad de 'cobrados' en la ciudad y villas de Santiago que disfrutaban de Fuero propio", en Boletín de la Real Academia Gallega, 309-320 (octubre 1956), pp. 1-31.

${ }^{4}$ Ibid., Galicia en tiempo de los Fonsecas, Madrid, 1957, pp. 144-145. Sobre la institución del pertiguero mayor de Santiago, véase además, A. LOPEZ FERREIRO, Fueros municipales de Santiago y su tierra, Madrid, 1975 ( $1^{\mathrm{a}}$ ed. 1895), específicamente cap. XXX, y R. PÉREZ BUSTAMANTE, El gobierno y la administración de los reinos de Castilla (1230-1474), Madrid, Universidad Autónoma, 1976, 2 tms; en concreto, I, pp. 275-285.
}

"CUADERnOS DE ESTUdIOS GALLEGOS", Tomo XLI, Fascículo 106, Santiago 1993-94. 
zó categoría como ente jurídico definido y autónomo dentro del organigrama episcopal. Pero, desde luego, durante los decenios finales del XV y primeros de la centuria siguiente - máxime en el período de tránsito a la modernidad (1470/80-1520/35) - ya se constata un claro fortalecimiento funcional de la institución, encaminado a convertirla en instrumento supremo del Arzobispo en lo temporal; a los efectos de lo que aquí interesa, instancia superior dentro de la jerarquía de sus tribunales laicos ${ }^{5}$. En este sentido sus potestades jurisdiccionales llegaron a ser muy amplias, pudiendo conocer en $1^{\mathrm{a}}$ instancia de todas las causas civiles y criminales $a$ prevención y acumulativamente con los alcaldes ordinarios (y justicias locales) de todo el arzobispado, y en grado de apelación de cualesquier causas que ante él se interpusieran de las sentencias de dichos alcaldes ordinarios u otras justicias locales dependientes del Arzobispo; o sea, era a la vez juez ordinario y juez de apelaciones de las resoluciones de los inferiores.

Además del alcalde mayor o asistente tenían adheridas y ejercían funciones (jurisdiccionales) contenciosas en lo temporal otras justicias seglares $\mathrm{y}$, sin perjuicio de su naturaleza eclesiástica, también por delegación y/o nombramiento arzobispal, el provisor o gobernador del arzobispado y vicario general apostólico y dos jueces eclesiásticos llamados de la quintana.

Específicamente, el provisor fue, junto con el asistente, "juez ordinario de apelaciones" de todo el dominio arzobispal hasta 1566. Incluso, nos atreveríamos a sugerir, se convirtió en el "juez de apelaciones" por excelencia, lo menos a partir de 1535/40 cuando la Mitra compostelana empieza a estar ocupada por prelados absentistas, al poder entonces desde su privilegiada posición - como "alter ego" del arzobispo, que tiene reasumido todos sus poderes - atraer hacia sí (por mecanismos que no viene al caso explicar ahora) el conocimiento de asuntos en perjuicio del asistente. Por su parte, los jueces eclesiásticos de la quintana estaban facultados para conocer asimismo en $1^{\mathrm{a}}$ y $2^{\mathrm{a}}$ instancia de lo que fuera contra derecho en cualesquier causas "mere profanas" (así civiles como criminales), aunque en la práctica sólo lo hacían de asuntos concretos (huérfanos, minorías de edad, etc.).

${ }^{5}$ Cuestiones ambas que tratamos y demostramos cumplidamente en otro lugar (M. LÓPEZ DÍAZ, El señorio episcopal urbano en Galicia, siglos XVI-XVII, tesis doctoral inédita, leída en la Universidad de Santiago, julio de 1994, esp. cap. II. Para lo que viene a continuación remitimos asimismo al epígrafe V.3.1, pp. 209-214 (donde se trata de la organización judicial en el dominio del prelado compostelano.

"CUADERNOS DE ESTUDIOS GALLEGOS", Tomo XLI, Fascículo 106, Santiago 1993-94. 
En este contexto los primeros pasos hacia la reforma de los tribunales o audiencias arzobispales e institucionalización del juez seglar de la quintana se dieron en 1545, a raíz de una Real Provisión ganada por el concejo compostelano en el Consejo, previa denuncia de que en la ciudad, además de las justicias laicas, el señor (Prelado) nombraba jueces clérigos (provisor y jueces eclesiásticos de la quintana) que conocían de las causas temporales; lo cual - decían - era "contra todo derecho", en clara referencia a las pragmáticas dadas por los Reyes Católicos en 1500 y 1502 y sobrecarta de su hija Dña. Juana expedida en 1514, en las cuales se mandaba al Arzobispo de Santiago, Obispos y demás que tuvieren jurisdicción temporal en el Reino de Galicia pusiesen personas legas que la ejerciesen, y que éstas procediesen como jueces temporales y no eclesiásticos ${ }^{6}$. Asimismo denunciaban que dichas justicias clérigas causaban muchos y grandes agravios a los vecinos de la ciudad por no dar fianzas al posesionarse de sus cargos ni estar sujetos a juicio de residencia al abandonarlos. Precisamente en la Real Cédula despachada por el Príncipe Felipe (con fecha de 4.4.1545) se mandaba al Prelado que proveyese medios para que la persona o personas que habían usado o usaren de jurisdicción temporal en la ciudad diesen fianzas y fiadores ante escribano del ayuntamiento y se obligasen a dar residencia por el tiempo que hubieren ejercido o ejerciesen dicha jurisdicción temporal, conforme estaba estipulado en la normativa real para todos los jueces ordinarios y delegados ${ }^{7}$. Y a instancia de dicha providencia el entonces titular de la diócesis -Arzobispo Don Gaspar de Abalos - se planteó reformar el organigrama de sus tribunales de justicia. En lugar de los dos jueces clérigos de la quintana que conocían de todo tipo de causas y a los cuales por su condición eclesiástica difícilmente se podía tomar residencia, propuso nombrar uno clérigo para las causas de esta naturaleza y otro laico para las temporales, llamados juez eclesiástico y juez ordinario de la quintana, respectivamente ${ }^{8}$.

${ }^{6}$ N.R.: 1, 3, 8 (=Nov. R.: II, 1, 10). A posteriori fue ratificada por Felipe II, en Cortes de Valladolid de 1558, pet. 22 y por pragmática de 1565. Así lo recoge también la literatura jurídica; entre otros: CASTILLO DE BOVADILLA, Política para corregidores y señores de vasallos, Madrid, 1978 (reed. en facsímil de la publicación hecha en Amberes, en 1704), esp. Lib. II, XVII, núm. 194, p. 538, y HEVIA BOLAÑOS, Curia Philipica, Madrid, 1753 (reimp. de la ed. de 1657), sec. I, parr., 2, núm. 18, p. 11.

${ }^{7}$ Archivo Histórico Diocesano de Santiago (en adelante, A.H.D.S.), Informaciones varias, leg. 1230 , ff. $66-66 \mathrm{v}^{\circ}$ (donde se contiene una copia de la citada Real Provisión).

${ }^{8}$ Según refiere A. LÓPEZ FERREIRO, Historia de la S.A.M. Iglesia de Santiago de Compostela, Santiago de Compostela, 1905-1909; en concreto, t. VIII, pp. 111-112.

"CUADERNOS DE ESTUdIOS GALLEGOS", Tomo XLI, Fascículo 106, Santiago 1993-94. 
Sin embargo, ese salto cualitativo o reorganización - que sepamosno se llevó a cabo hasta 1566, fecha en que se ratificó la prohibición formal a los Prelados y demás señores con jurisdicción temporal de nombrar personas clérigas para ejercerla (pragmática de 1566, confirmatoria de las ya citadas de 1500,1502 y 1514$)^{9}$. Como novedad respecto a las anteriores, la nueva orden goza de aceptación y se aplica casi de inmediato, en buena medida — pensamos - porque estaba sancionada por las disposiciones conciliares tridentinas, y así se recomendó también a partir de entonces en los concilios sinodales ${ }^{10}$. Pero por si la explicación pudiera parecer insuficiente, hay otros testimonios que corroboran nuestra afirmación. El mismo López Ferreiro nos ofrece alguno: un breve repaso a la provisión de cargos efectuada por el capítulo catedralicio durante los períodos de sede vacante que hubo después de 1545 y que el citado autor recoge en su obra, pone de manifiesto que tras aquel primer proyecto se continuaron nombrando como jueces de la quintana dos clérigos ${ }^{11}$. Por

\footnotetext{
${ }^{9}$ Reléase, supra, nota 6 .

${ }^{10}$ Así lo dejan entrever, al menos, algunos testigos en el pleito que en 1593 litigaron los escribanos del juez ordinario de la quintana con el alcalde mayor del arzobispo; en concreto, a las preguntas segunda ("Si sabe que antes de la publicación del Santo Concilio de Trento los provisores del Arzobispado de Santiago conoscían de todas las causas cibiles y profanas entre qualesquier personas seglares que ellos pedían justicia y así se usaba") y tercera ("si sabe que antes de la publicación del Santo Concilio de Trento, los Provisores conocían asimismo de todas las apelaciones que se interponían para delante dellos de las sentencias de causas civiles y profanas que sentenciaba el juez de la quintana, las quales apelaciones no iban al dicho tiempo delante el alcalde Mayor, sino delante dichos Provisores y esto se usaba por costumbre i estilo guardado por los arzobispos de Santiago"), el testigo y escribano Miguel Gayoso responde afirmativamente (Archivo del Reino de Galicia, en adelante A.R.G., Pleitos de vecinos, leg. $1177, \mathrm{n}^{\circ} 28$ ). Con independencia de la veracidad y parcialidad de las respuestas, cuanto menos parece acreditada la relación causa-efecto de ambos hechos que se reiterará treinta años después.

"Así en la sede vacante tras el pontificado del mismo arzobispo Don Gaspar de Abalos que concluyó en 1545, el cabildo nombró entre otros cargos como jueces de la quintana al cardenal Juan de Ozpina y al canónigo Martín Fernández de Salinas. De forma análoga, en sede vacante (después del fallecimiento del arzobispo Don Pedro Manuel a comienzos del año 1550) designó como jueces de la quintana a los canónigos Eliseo de las Alas y Juan López de Sanjuán. Y en la vacante siguiente que se prolongó desde septiembre de 1557 (fallecimiento del arzobispo Don Juan Álvarez) hasta el 11 de febrero de 1559 (en que tomó posesión de la Iglesia compostelana el hasta entonces obispo de Segovia, Don Gaspar de Zúñiga y Avellaneda) el capítulo catedralicio eligió como jueces de la quintana a la dignidad y tesorero Lope Raposo y al canónigo Juan López de Sanjuán (según los datos que ofrece A. LOPEZ FERREIRO, Historia, op. cit., VIII, pp. 115, 119 y 132, respectivamente).
}

"CUADERNOS DE ESTUDIOS GALLEGOS", Tomo XLI, Fascículo 106, Santiago 1993-94. 
otro lado, en las actas de consistorio del ayuntamiento tampoco se hace mención expresa a la existencia del juez seglar de la quintana hasta el año 1567 y aun entonces para rechazarlo, aduciendo que era "cosa que jamás nunca fuera vista ni usada porque los Juezes de la Quintana que asta agora abían sido heran clérigos y no legos ${ }^{12 "}$.

A partir de 1566 y hasta 1600 se afirmó la separación orgánica y funcional de ambas magistraturas. En consecuencia y a nuestros efectos, el juez seglar de la quintana se configuró paulatinamente como unjuez arzobispal ordinario y de apelaciones, mayormente por la vía de nombrarlo "juez de residencia" y prorrogar sucesivamente su comisión, provocando con ello infinidad de conflictos con el concejo y alcaldes ordinarios compostelanos que trataban de deslegitimar su existencia (mediante pleito) ante los tribunales reales, aduciendo que era un cargo creado de nuevo y que con las mencionadas prórrogas el Arzobispo trataba de "adelantar" su jurisdicción y "menguar" la $1^{\mathrm{a}}$ instancia municipal, perjudicando a las justicias ordinarias $^{13}$, pues - no hay que olvidar- durante las residencias se suspendía la jurisdicción de los alcaldes (residenciados), reasumiéndola toda el juez comisionado. A la postre, sin embargo, la oligarquía dirigente acabó aceptando la institucionalización de la magistratura como capítulo de la concordia que firmó en 1600 con el Arzobispo San Clemente, pero con una significativa excepción en sus competencias: "que no pudiese conocer en $1^{\mathrm{a}}$ instancia de ningún negocio tocante al gobierno de la ciudad" (concordia de 6.8.1600, cap. 3) ${ }^{14}$; los cuales quedaban así sancionados como jurisdicción privativa del regimiento y justicias ordinarias.

Más allá de esta fecha el cargo se consolidó como órgano judicial autónomo y permanente - se entiende, por oposición a la intermitencia e

${ }^{12}$ Archivo Histórico de la Universidad de Santiago (en adelante A.H.U.S.), Libro de consistorio (en adelante L.C.) de 1567, (Consistorio o Concejo, en adelante C.O.) 15-IX, f. 265: Se acuerda pedir al arzobispo que deje sin efecto tal nombramiento.

${ }^{13}$ Tratamos ampliamente la cuestión en otro lugar; concretamente, El señorio, op. cit., en epígrafe IV.4 titulado "Del reforzamiento de las prerrogativas judiciales señoriales (15781598)", pp. 144-1554.

${ }^{14}$ A.H.D.S., Serie jurisdiccional, leg. 93, ff. 1-100: "Carta ejecutoria dada en favor del Sr. Maximiliano de Austria, Obispo y señor de la Santa Iglesia, ciudad e Arzobispado de Santiago, en el pleito con la Justicia y Regimiento de dicha ciudad, sobre jurisdicción y vasallaje de dicha ciudad y sobre la concordia hecha entre el dicho Arzobispo y la ciudad"; esp. el texto del acuerdo, ff. 77-80. Una copia de la citada concordia y ejecutoria puede verse también en A.H.U.S., Libro de Ejecutorias, Reales Provisiones y otros documentos, siglos XVII y XVIII, f. 1-65.

"CUADERNOS DE ESTUDIOS GALLEGOS", Tomo XLI, Fascículo 106, Santiago 1993-94. 
inconcreción jurisdiccional que había tenido en la etapa anterior- lo cual no quiere decir que finalizaran las tensiones e interferencias entre el poder señorial y poder municipal compostelano respecto a este oficio. Antes al contrario, las hubo, aunque ahora centradas en su actuación jurisdiccional, sobre todo en el conocimiento de los asuntos de gobernación (o policía) de la ciudad, en los que a menudo el juez de la quintana trataba de intervenir, so pretexto de hacerlo en alzada o por vía "de relación e agravio" de las resoluciones del concejo y justicias ordinarias, y no en la $1^{\text {a }}$ instancia como éstos pretendían, defendiendo su conocimiento privativo tanto si el asunto era judicial como extrajudicial —anótese, en función del acto que le daba lugar ${ }^{15}$.

Desde el punto de vista jurídico el juez ordinario de la quintana tenía en principio las mismas competencias que el asistente (conocimiento en $1^{\text {a }}$ instancia a prevención con los alcaldes ordinarios en la ciudad y Giro de la Rocha ${ }^{16}$ y en grado de apelación de todo el dominio episcopal. Pero con una sustancial diferencia que consignaba la jerarquización interna de ambas magistraturas: de sus sentencias se podía apelar al citado asistente (o alcalde mayor) antes de acceder a la Real Audiencia, pero no a la inversa. Haciendo buena la máxima de que "la apelación prueba superioridad"17,

\footnotetext{
${ }^{15}$ Remitimos asimismo a nuestro trabajo, El señorio, op. cit., pp. 225-239.

${ }^{16}$ Esto operaba fundamentalmente con relación a la ciudad de Santiago y sus términos donde estaba asentada la administración (y tribunales) señoriales, cuanto menos a partir de 1622. De hecho, en este año, con fecha de 11 de marzo, el arzobispo don Juan Beltrán de Guevara, en consideración a "los daños, vexaciones e intereses que se siguen a nuestros súbditos y vasallos por las denunciaciones que diferentes personas desta ciudad hacen ante los jueces hordinarios della contra vecinos y moradores de otros juzgados deste nuestro arzobispado, vasallos nuestros, sacándoles de sus casas y lugares maliciosamente y por causas a esta ciudad", despachó una orden mandando al asistente y juez de la quintana que en adelante no admitieran denuncia alguna de los vasallos de las jurisdicciones de aquélla bajo su dominio, salvo que "sean ehas y firmadas por vecinos y naturales del mismo lugar o feligresía de donde fuere el acusado, ni despachen mandamiento alguno con ocasión de semejante denunciación, con apercibimiento que se procediera contra los executores que los llevaren" (A.H.D.S., Serie jurisdiccional, leg. 94).

${ }^{17}$ Según se lee en la Librería de Jueces Utilisima y Universal, Madrid, 1771, t. II, p. 52, cuyo autor es M. SYLVESTRE MARTINEZ: "La apelación prueba superioridad porque ésta siempre sigue el orden de inferior a superior" (citado por S. AIKIN ARALUCE, El recurso de apelación en el derecho castellano, Madrid, 1982, p. 11, nota 31); lo mismo se advierte en la glosa de AZZO: "appellatio debet fieri ad superiorem, id este eum qui est in grado proximo superiori eo, qui tulit sententiam" (Suma Codicis, /, 62, de appel., $\mathrm{n}^{\circ} 32$, recogido en op. cit. supra, nota 32 , quien a su vez la toma de A. PADOA SCHIOPPA, Ricerche sull'appello nel diritto intermedio, II. I Glossatori Civilisti Milán, 1967, p. 110).
}

"CUADERNOS DE ESTUdIOS GALLEGOS", Tomo XLI, Fascículo 106, Santiago 1993-94. 
el juez de la quintana era "igual" o "inferior" al asistente, según el grado en que conociera. El problema que se plantea entonces es si conociendo éste como juez de apelaciones, el asistente tenía igualmente facultad para revisar sus dictámenes. Dicho de otra forma, si podía haber más de dos grados de jurisdicción (doble apelación señorial) antes de que un caso fuera al tribunal real, tal y como ocurría por ejemplo en algunos señoríos franceses ${ }^{18}$. Para resolver este aspecto de forma concluyente sería necesario un trabajo de archivo sobre su quehacer judicial (seguimiento de pleitos y causas en que aquél intervino), el cual no hemos tenido ocasión de efectuar. Pero, a falta de ello, con las fuentes que manejamos algo se puede apuntar, aunque sólo sea como mera hipótesis.

De entrada hemos de indicar que en la fase inicial esta circunstancia ni se planteó. Ya se advirtió: con relación a la ciudad de Santiago y Giro de la Rocha, el juez seglar de la quintana se concibió y "consolidó", esencialmente, como un juez señorial de $1^{\mathrm{a}}$ instancia añadido o "alternativo" a los alcaldes ordinarios. $Y$ con respecto al resto de las jurisdicciones del dominio arzobispal como "juez de apelaciones", sin perjuicio de que en ocasiones avocase causas, incluso conociese a prevención en $1^{\text {a }}$ instancia junto a los jueces locales ${ }^{19}$. En uno y otro caso, se respetó básicamente la letra de las Reales Cédulas y (para la ciudad) de la carta ejecutoria de 1569 que sólo daban y reconocían las $1^{\mathrm{a}}$ alzadas al Arzobispo ${ }^{20}$.

Ya en la etapa posterior, asentada la institución y avanzado el seiscientos, es posible que el poder señorial tratara de extender su jurisdicción en las apelaciones promoviendo esa $2^{\mathrm{a}}$ alzada del juez de la quintana al asistente. Pero en todo caso, si se dio — cuanto menos hay indicios de que se

${ }^{18} \mathrm{Cfr}$. R. MOUSNIER, The institutions of France under the Absolute Monarchy, 1598 1789, University of Chicago, Chicago, 1979, esp. pp. 523 ss.

${ }^{19}$ A.R.G., Pleitos de vecinos, leg. 752, $\mathrm{n}^{\circ} 21$ (año 1582): Pleito de la justicia y regimiento de Pontevedra contra el alcalde mayor de la ciudad y arzobispado de Santiago y el juez seglar de la quintana, en razón de que "se entrometían a sacar en primera instancia adbocando los negocios civiles y criminales / y trayéndolos y a las partes a la ciudad de Santiago que es a diez leguas de la dicha villa, sacándolos de su fuero y jurisdicción".

${ }^{20}$ A.H.D.S., Serie jurisdiccional, leg. 91: Carta Ejecutoria despachada por la Chancillería de Valladolid a pedimento del Arzobispo Don Gaspar de Zúñiga Avellaneda en el pleito que tuvo con el concejo y vecinos de la ciudad de Santiago (contiene sentencia de vista dada en Valladolid a 18 de mayo de 1548 y la confirmatoria en grado de revista de agosto de 1568).

"CUADERNOS DE ESTUDIOS GALLEGOS", Tomo XLI, Fascículo 106, Santiago 1993-94. 
intentó $^{21}$ - fue como una práctica viciosa y de alcance limitado, no adquiriendo sus titulares derecho alguno en este sentido. A tal propósito y aun a riesgo de caer en el excesivo casuismo, parece útil recordar aquí algunos extractos de una representación que hizo el Arzobispo Orozco (1738-45) con ocasión, precisamente, de un pleito procedente de una jurisdicción sufragánea, en el cual había conocido en $2^{\mathrm{a}}$ instancia el juez de la quintana y pretendía hacerlo en la sucesiva $\left(3^{\mathrm{a}}\right)$ el asistente ${ }^{22}$. El hecho es que una de las partes acudió ante la Real Audiencia y obtuvo un auto ordinario por el cual se mandaba que en todas las causas en que el juez de la quintana conociere como juez de apelaciones no se podía introducir agravio ni apelar al asistente, sino acudir directamente ante el Real Tribunal. Teniendo conocimiento de ello, el Prelado mandó a su abogado suplicase el citado auto,

"relacionándole la costumbre y estilo que avía de siglos a esta parte de apelarse del juez de la quintana al asistente de las causas en que conocía como juez de apelaciones, que esto se justificaría con testimonio de pleitos modernos y antiguos y con información de que no abía memoria de hombres que acordase otra cosa".

A lo cual aquél replicó, reprochándole al Arzobispo su total desinformación respecto del tema, la ilegalidad de lo que pretendía y, sobre todo, los perjuicios de judicializar un asunto, tal que era "usurpación de jurisdicción", perdido de antemano. Vale la pena transcribir aunque sólo sea parte de dicha declaración:

\footnotetext{
${ }^{21}$ Según denuncia en su petición el fiscal de la Real Audiencia y la propia ciudad, en una causa (y proceso) incoado en 1729 por el concejo compostelano de Santiago y alcalde ordinario contra el arzobispo y su alcalde mayor (o asistente): "Respecto de las apelaciones por el Reverendo Arçobispo se pretende (...) y que de las [causas] civiles se concedió sin diferencia de jueces, pudiéndose apelar para los maiores entendiéndose esto o para el Asistente o para el Juez de la Quintana, teniendo título de juez maior pero no para entrambos subcesivamente como se a yntentado practicar contra lo expresamente decidido y aun confesado por el Reverendo Arçobispo quando después de las sentencias de los años mill quinientos quarenta y ocho, mill quinientos sesenta y ocho y mill quinientos noventa y dos representó que esta Audiencia no se reglava a ellas yntroduciéndose a conocer ynmediatamente de las sentencias de sus Justicias hordinarias, pudiéndolo únicamente acer de las dadas en grado de Apelaciones por el Asistente o Juez de la Quintana" (A.H.D.S., Serie jurisdiccional, leg. 95 (año 1729), ff. 38v-39).

${ }^{22}$ Ibidem, Expediente de los años 1733-1738 (está sin numerar, por eso se cita por los años): Toca a la jurisdicción del asistente y del juez seglar de la quintana.
}

"CUADERNOS DE ESTUdiOS GALLEGOS", Tomo XLI, Fascículo 106, Santiago 1993-94. 
"Comtemplo a V.I. muy mal informado. Nada sirve conste por pleitos, que el Asistente conoció así y que aiga un millón de testigos que lo digan; pues también constará por muchos que se admitieron las primeras apelaciones en la Audiencia y que corrieron millares de cosas contrarias a las executorias. Lo que verdadera y lexítimamente consta es que sólo el Rei concedió a la Dignidad las primeras apelaciones, en todos los tiempos subcesivos hasta aora jamás dijo algo de los Sres. Arzobispos tenían más privilegio que el que parece terminado a dicho grado"23.

$\mathrm{Y}$ aun cuando es forzoso reconocer que el espíritu que anima tan contundende respuesta no se puede desligar de los tiempos en que se formula (casi mediados del XVIII), también lo es admitir, con mayor razón, que su autor conocía a la perfección la realidad práctico-jurídica que operaba en el asunto, acaso porque no era nuevo. De hecho, el proceso no se siguió.

A mayor abundamiento, por si todo esto pudiera parecer insuficiente a los efectos de apuntalar cuando arriba se ha dicho, conviene recordar también que la doctrina predominante consideraba viciosa y, por tanto, inválida la costumbre de apelar al juez "igual" o "inferior"24. Del mismo modo, en el contexto de los señoríos se cuestionaba el derecho del señor para revisar las sentencias de su alcalde mayor (conociera éste en $1^{\mathrm{a}}$ instancia o en apelación), fundamentada la negativa en que jurídicamente eran "el

${ }^{23}$ Y continúa así: "Los perjuicios que enbuelve salir del que hai, y esta egecutado son dignos de considerarse. Los principales son los inútiles gastos que se causan a los vasallos, en el seguimiento de una instancia, que no tiene el Asistente, ni les sirbe, y la usurpación de jurisdicción que no se, si el que leió el extracto reconoce el derecho que sólo tiene la Dignidad y dijeron los Sres. Prelados sólo tenía, tendrá seguridad de conciencia en meterse a conocer y determinar por tal grado en segundas apelaciones.

Manda V.I. que se apele del Auto que digo a V.I. el Asistente no puede ser, ni es raçón se aga en nombre de tan gran Prelado cosa que no lleva camino, ni tiene átomo siquiera de razón, y es más gloria enmendar por sí lo que no se hace bien, que esperar lo enmiende otro..." (Ibidem).

${ }^{24}$ Cfr. S. AIKIN ARALUCE, El recurso, op. cit., p. 24, citando como fuente a GREGORIO LÓPEZ en sus Glosas, 3, 23, 1 ("Et non tenet consuetudo apellandi ad parem vel minorem: qui esset contra naturam appellationes...") y a SCACCIA en se Tractatus de Appellanionibus, Lieja, 1625, q. 2, cap. 1, num. 5-14, p. 4.

"CUADERNOS DE ESTUDIOS GALLEGOS", Tomo XLI, Fascículo 106, Santiago 1993-94. 
mismo, uno e igual tribunal"25. Cuanto más se entendería aplicado al caso que nos ocupa, como lo reclamaba en sus alegaciones el fiscal real, pues "de poderse apelar de éste [juez de la quintana] al Asistente se siguiera apelar dos veces a un mismo juzgado del Dueño y de ygual a ygual juez, de dever ser entrambos maiores para poderse apelar a qualquiera de ellos (...), además de seguirse el absurdo contra lo expressamente decidido, de que siendo conformes las sentencias del Asistente y juez de la quintana a la justicia hordinaria arían ejecutoria sin yntervención del tribunal Real", en contra de lo prevenido en las sentencias de la Chancillería y Reales Cédulas del Consejo ${ }^{26}$.

Vistas así las cosas - y ésta es la razón de que nos hayamos extendido en las explicaciones teórico-testimoniales - parece claro que fuera cual fuera el alcance que tuviera esa práctica, incluso el mero intento de ampliar la jurisdicción por esta vía, estaría en línea con el planteamiento que en su día hiciera el profesor R. Kagan de un retroceso de la justicia real durante la centuria del XVII en beneficio de los poderes y tribunales periféricos, sobre todo municipales y señoriales ${ }^{27}$, y viceversa, para el XVIII. Pero, además, bien pudiera suceder que ese mismo retraimiento jugara - por viciosa que fuera la práctica- a favor de la doble instancia señorial (no sólo $1^{\mathrm{a}}$ y $2^{\mathrm{a}}$ si el juez de la quintana actuaba como juez ordinario y el asistente conocía en la misma como juez de apelaciones, supuesto acreditado en la documentación, sino también $2^{\mathrm{a}}$ y $3^{\mathrm{a}}$ o doble apelación si aquél conocía como juez de apelaciones primero y éste como segundo;

${ }^{25}$ Así lo describe HEVIA BOLAÑOS, Curia, op. cit., p. V, parr. 1, num. 8-9, p. 244; y en términos parecidos se expresa CASTILLO DE BOVADILLA, Política, op. cit., Lib. II, c. XVI, num. 76, p. 460: "porque siendo como es un mismo tribunal el del Juez y el del señor que lo puso no pueden apelarse del uno para el otro", según expone siguiendo la fundamentación jurídica de COVARRUBIAS, quien a su vez lo hacía sobre la de BARTOLO. En todo caso, todos reconocen la capacidad de los títulos y costumbre para excepcionar frente a la ley general. Castillo de Bovadilla incluso va más allá: constándole que se practica, en el número siguiente anota que "de los alcaldes Mayores y Governadores, conociendo en primera instancia se apela para ante los Señores" -y añade a continuación- aunque "en las Chancillerías se revocan siempre sus sentencias por defecto de jurisdicción no embargante que sean justas".

${ }^{26}$ A.H.D.S., Serie jurisdiccional, leg. 95 (año 1729): Continuación de alegación fiscal en la causa que litigaba la ciudad y el arzobispo y su alcalde mayor en la Real Audiencia.

${ }^{27}$ R. KAGAN, Lawsuits and litigants in Castile, 1500-1700, Chapel Hill, 1981, esp. pp. 210-246; también del mismo autor, "Pleitos y poder real. La Chancillería de Valladolid (1500-1700)", en Cuadernos de Investigación Histórica, 2 (1978), pp. 291-316.

"CUADERnOS DE ESTUdiOS GALLEGOS", Tomo XLI, Fascículo 106, Santiago 1993-94. 
esto es, una segunda alzada al asistente), ya que si ninguna de las partes, fuera o no conforme con su dictamen, apelaba la Real Tribunal teniendo derecho a hacerlo - en general, si se registra un descenso en la alzadadifícilmente se podía revocar sus sentencias por "defecto y jurisdicción" $\mathrm{y}$, en último extremo, plantear medidas para evitarlo. De todas maneras - insistimos - es una posibilidad que en el futuro deberá dilucidarse con investigaciones concretas sobre la práctica (léase, pleitos).

Por lo que se refiere a otros aspectos de la institución, durante el período que abarca este trabajo el cargo estuvo ocupado como el de asistente por letrados designados directamente por el Arzobispo, si bien su duración era trienal. En teoría, porque en la práctica, al igual que ocurría con otras magistraturas, este requisito tendió a ser transgredido, dificultando con ello la exigencia de responsabilidades (de los interesados) ${ }^{28}$. Añadamos aún que un sector importante accedió a posteriori al oficio de alcalde mayor o asistente - hecho habitual, cuanto menos en la segunda mitad del XVI y primera de la centuria siguiente - en tanto que no registramos promoción alguna en sentido inverso. Lo cual demuestra, también en este aspecto, la particular jerarquización que existía por debajo de la aparente simultaneidad competencial entre las dos instituciones y que progresivamente se debió ir acentuando. Hay un dato bien significativo en este sentido: a comienzos del seiscientos, según Jerónimo del Hoyo los ingresos por el ejercicio de los oficios eran ligeramente favorables al juez de la quintana, previsiblemente por su mayor actividad en la $1^{\mathrm{a}}$ instancia (en torno a 5.000 reales anuales, frente a los 4.000 que consignaba al asistente, incluido salario y ayuda de $\operatorname{costas}^{29}$ ); un siglo y medio más tarde sus gratificaciones habían aumentado en un 25 y $175 \%$, respectivamente ${ }^{30}$. Y

\footnotetext{
${ }^{28}$ Según Real Provisión de 1 de marzo de 1543 los oficios y cargos de justicia proveídos por los Prelados, Caballeros y demás personas con jurisdicción en el Reino estaban obligados a hacer residencia de tres en tres años (Ordenanzas de la Real Audiencia de Galicia, La Coruña, Antonio Frayz, 1679, p. 190). Como testimonio del incumplimiento véase la denuncia que se recoge en A.M.S., L.C. de 1614, C.O. XII, f. 40: Se acuerda pedir al cabildo quite la vara de juez seglar de la quintana al licenciado Juan Ruiz Ribera, atento que no podía ser reelegido hasta pasar "hueco" y tener dada residencia.

${ }^{29}$ J. del HOYO, Memorias del arzobispado de Santiago, ed. A. Rodríguez y B. Varela Jácome, s.f., pp. 5-6.

${ }^{30}$ Según datos tomados de J.M. GONZÁLEZ FERNÁNDEZ, La justicia señorial en la Galicia del siglo XVIII, Universidad de Santiago, 1984 (tesina de licenciatura inédita), p. 47.
}

"CUADERNOS DE ESTUDIOS GALLEGOS", Tomo XLI, Fascículo 106, Santiago 1993-94. 
es que la devaluación que se aprecia en el primer órgano respecto al segundo nada tiene que ver con la pérdida de atribuciones, como se ha sugerido, pues ambos eran "justicias mayores". Luego acaso tuviera que ver (y mucho) con una distribución orgánica de funciones más racional o, si se prefiere, una progresiva especialización y autonomía, donde prima el principio de verticalidad (o jerarquización) sobre la acumulación.

Para concluir, la audiencia del juez seglar de la quintana en cuanto a dotación se completaba con seis escribanías numerarias renunciables (que compartía con su homólogo eclesiástico) y cinco ministros inferiores o subalternos $^{31}$. Por su parte, el asistente contaba con dos escribanías del número renunciables y un número variable de ministros (de ocho a diez en torno a 1623, dos o tres de los cuales le "acompañaban" y executaban sus mandatos en la ciudad ${ }^{32}$ ). Aparte, ambas magistraturas compartían los servicios del aguacil mayor, un oficial nombrado directamente por los prelados que tenía como misión asistir a las justicias arzobispales (fueran clérigas o laicas) en todas sus actividades. En tiempos el poder señorial pretendió que fueran dos los cargos de estas características ${ }^{33} \mathrm{y}$, fracasada esta vía, se reconoció al titular-propietario derecho para designar teniente que le sustituyera en sus ausencias, lo cual hizo aumentar, más si cabe, las tensiones con las autoridades locales al pretender aquél ampliar su jurisdicción institucionalizando la excusación de manera permanente ${ }^{34}$.

${ }^{31}$ A.R.G., Pleitos de vecinos, leg. 1177, n 28 (año 1593): Los escribanos del juez ordinario de la quintana con los del alcalde mayor sobre "entregar pleitos originales"; asimismo A.H.D.S., Serie jurisdiccional, leg. 95 (Provisiones seculares de escribanías numerarias de Santiago).

${ }^{32}$ A.R.G., Pleitos de vecinos, leg. 10313, n 57 (año 1625): La justicia y regimiento de la ciudad de Santiago con el alcalde mayor de la ciudad sobre tener más de dos alguaciles $\mathrm{y}$ hacer extorsiones.

${ }^{33}$ A.H.U.S., L.C. de 1579, C.O. 19-III, f. 255v: Protesta elevada al prelado sobre la existencia de dos "aguaciles mayores" en contra de lo mandado por la carta ejecutoria.

${ }^{34}$ Sirvan como ejemplos los siguientes: Ibidem, L.C. de 1615, C.O. 1-VI, f. 70v: El concejo es informado de que se ha visto en dicho día a un teniente de aguacil mayor con vara alta de justicia que ejecuta y ronda por la noche "no pudiendo hacerlo por estar en esta ciudad el aguacil mayor propietario"; se acuerda hablar al Arzobispo Buxía "para que ponga en esto remedio"; L.C. de 1618, C.O. 23-V, f. 167v; L.C. de 1645, C.O. 18-VIII, f. $156 \mathrm{v}$, donde se registran quejas similares.

"CUADERNOS DE ESTUDIOS GALLEGOS", Tomo XLI, Fascículo 106, Santiago 1993-94. 